\section{Unilateral pulmonary oedema in a patient with hypertrophic cardiomyopathy and severe narrowing of the left pulmonary artery}

\author{
Y Turberg, F J Ricou, J C Chevrolet
}

Hôpital cantonal universitaire, Geneva, Switzerland

Clinique médicale Y Turberg

Centre de Cardiologie F J Ricou

Soins intensifs

medicaux

J C Chevrolet

Address for reprint requests:

Dr J C Chevrolet,

Soins intensifs medicaux,

Hôpital cantonal

Hopital cantonal
universitaire, 1211 Geneva 4,

universitaire,

Accepted 5 March 1990

A 32 year old Iranian woman was admitted to

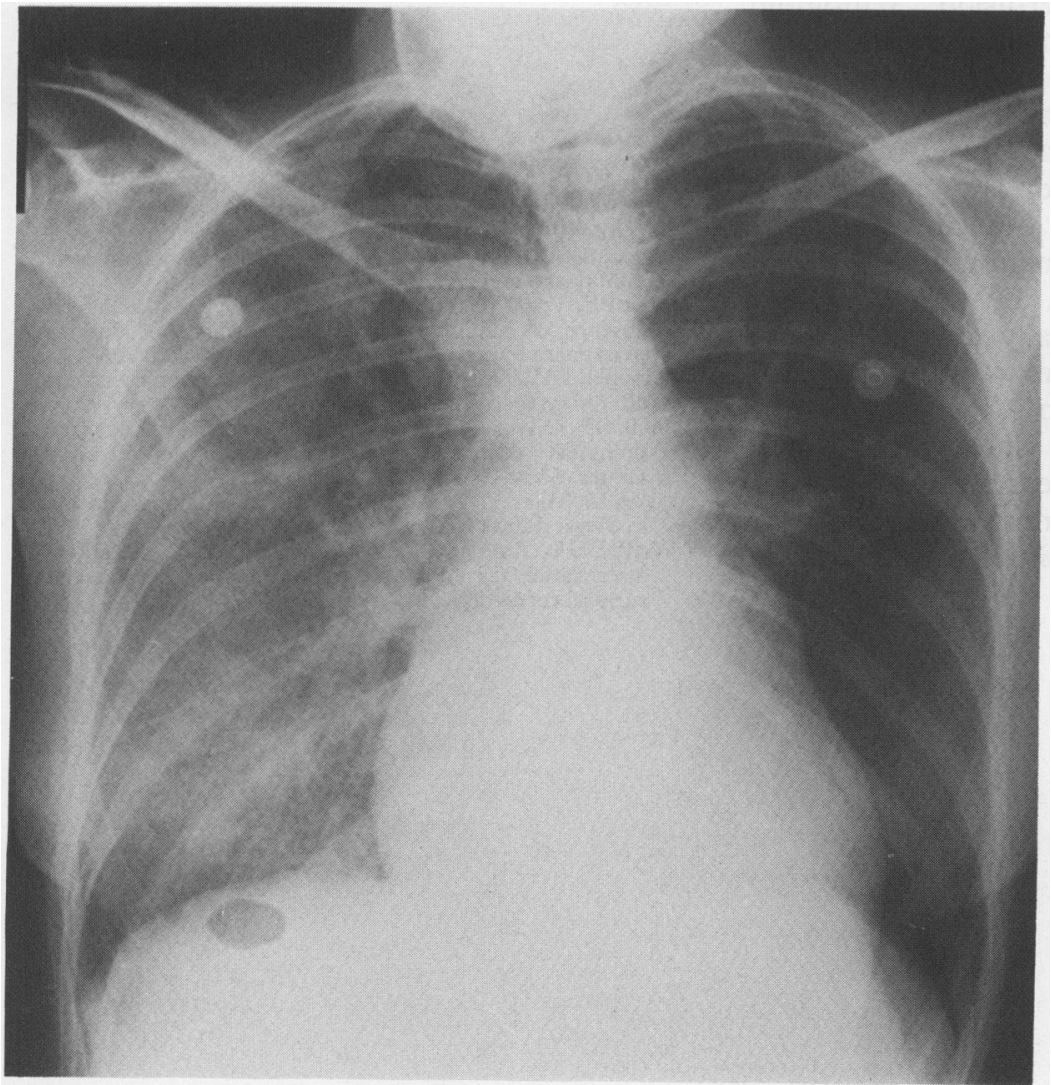

Figure 1 Chest radiograph at admission showing moderate cardiomegaly and right sided unilateral pulmonary oedema. hospital with a one day history of malaise and dyspnoea. She had been well until 1985, when progressive exertional dyspnoea developed and a diagnosis of hypertrophic cardiomyopathy was made on the basis of echocardiographic and catheter findings (Pittsburgh, USA). Subsequently her symptoms were controlled with propranolol $120 \mathrm{mg}$ twice daily and later with sotalol $480 \mathrm{mg}$ daily. This was introduced because short episodes of asymptomatic ventricular tachycardia were noted on a 24 hour ECG recording. In the few weeks before admission she experienced several episodes of syncope during emotional stress.

Her past medical history was otherwise unremarkable; she had had two normal pregnancies terminating in a caesarian section. She gave a family history of hypertrophic cardiomyopathy, which had affected her maternal grandfather and two uncles, none of whom had died suddenly. A non-smoker, she denied symptoms of chest pain, nocturia, oedema, and palpitations.

On examination, the patient was tachypnoeic (28 breaths/min), centrally cyanosed, and hypotensive with a supine blood pressure of $90 / 60 \mathrm{~mm} \mathrm{Hg}$. Cardiac examination disclosed a left ventricular heave, an atrial gallop, and a 3-4/6 pansystolic murmur, audible at the left sternal edge and the apex and radiating towards the axilla. Scattered crepitations were heard throughout the right lung field and normal breath sounds on the left.

A chest radiograph confirmed that she had unilateral right sided pulmonary oedema with characteristic engorgement of the hilar vessels, and diffuse alveolar infiltration in a single butterfly wing distribution (fig 1). Moderate cardiomegaly was present (cardiothoracic index 1.2). The left lung field was normal. An electrocardiogram confirmed sinus rhythm with left axis deviation, signs of left ventricular hypertrophy (Sokolow $=37 \mathrm{~mm}$ ), and diffuse non-specific repolarisation changes. A full blood count showed a haemoglobin concentration of $13.4 \mathrm{mg} / \mathrm{dl}$ and a raised white cell count of $16.9 \times 10^{6} / 1(72 \%$ segmented neutrophils). Arterial blood gas analysis showed an arterial oxygen tension $\left(\mathrm{PaO}_{2}\right)$ of $5.80 \mathrm{kPa}$ and carbon dioxide tension $\left(\mathrm{PaCO}_{2}\right)$ of $4 \cdot 1 \mathrm{kPa}$ when the patient was breathing air.

An echocardiogram showed typical findings of hypertrophic cardiomyopathy with asymmetric septal hypertrophy $(28 \mathrm{~mm})$, systolic anterior motion of the anterior leaflet of the mitral valve, and a midsystolic closure of the aortic valve. A Doppler study showed a net acceleration of the flow in the left ventricular outflow tract of 4 metres a second.

The patient was treated in an intensive care unit with bed rest and oxygen. Sotalol was continued in view of the history of ventricular tachyarrhythmia. The symptoms improved rapidly and a chest radiograph 12 hours after admission showed dramatic resolution of the right sided pulmonary oedema.

In view of its antiarrhythmic and negative 


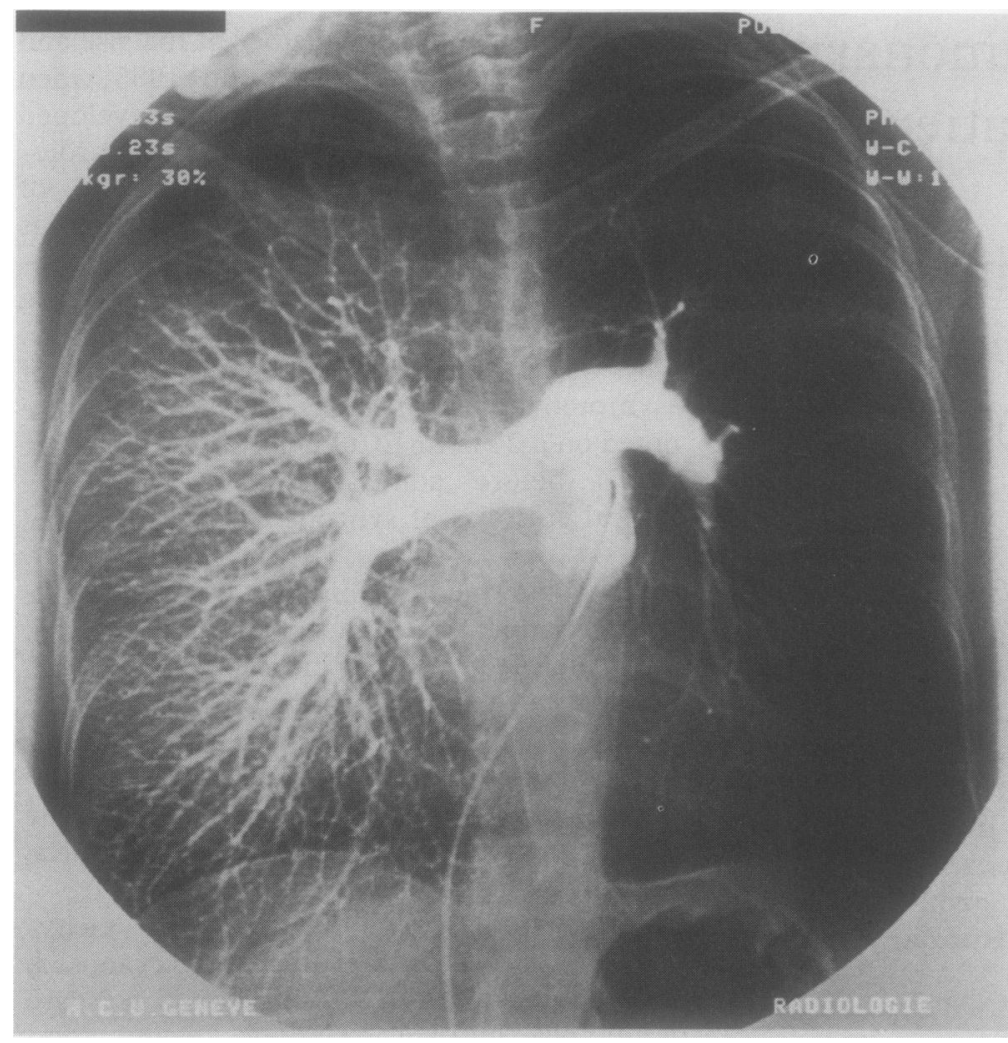

Figure 2 Pulmonary angiogram showing pronounced decrease in the calibre of the proximal branches of the left pulmonary artery.

inotropic effects, disopyramide $100 \mathrm{mg}$ thrice daily was introduced to reduce further the degree of obstruction at rest. $^{2}$ A forced expiratory chest radiograph showed symmetrical air emptying, thus excluding left unilateral emphysema (McLeod's syndrome). A technetium-99m perfusion scintigram confirmed absence of perfusion of the entire left lung, whereas the xenon-127 ventilation scintigram was normal. At pulmonary angiography a normal sized main pulmonary artery with normal secondary and tertiary right pulmonary arterial branches was seen. In contrast, the left pulmonary artery was of normal calibre initially, but all secondary branches were substantially attenuated with minimal blood flow. There was no evidence of abnormal venous return or of pulmonary embolism in any of the anterior, posterior, oblique, or lateral recorded views. Pulmonary function studies gave normal results. Six months after the acute episode the patient was well.

\section{Discussion}

In the ipsilateral type of unilateral pulmonary oedema there is usually an acute alteration in the alveolar capillary membrane in the affected lung, as in unilateral veno-occlusive disease or rapid pleural aspiration. ${ }^{34}$ In pathological conditions associated with a perfusion defect of one lung pulmonary oedema may occur in the normally perfused lung (contralateral type), as in cardiac decompensation. ${ }^{35}$ This may occur in pulmonary thromboembolism and McLeod's syndrome, ${ }^{6}$ and when there is proximal interruption of the pulmonary artery. ${ }^{7}$ Our patient presented with decompensated hypertrophic cardiomyopathy and unilateral right sided pulmonary oedema. The unusual presentation was accounted for by the proximal interruption of the left pulmonary artery clearly seen at angiography. Proximal interruption or unilateral absence of the pulmonary artery is a rare congenital anomaly, and is asymptomatic in the absence of pulmonary arterial hypertension or associated cardiovascular abnormalities. ${ }^{7}$

Pool et $a l^{\beta}$ reported accurately documented cases of proximal interruption of a pulmonary artery. Most occurred with a cardiovascular anomaly, most frequently patent ductus arteriosus, septal defects, and Fallot's tetralogy. No case was associated with hypertrophic cardiomyopathy and we cannot find such an association in the published reports. The reason for the cardiac decompensation in our patient is not clear. As it occurred at night and responded to minimal treatment we wondered whether it might be due to a dysrhythmia but have no direct proof of this.

1 Pollick C, Kimball B, Henderson M, Wigle D Disopyramide in hypertrophic cardiomyopathy. $A m$ J Cardiol 1988;62:1248-55.

2 Calenoff L, Kruglik GD, Woodruff A. Unilateral pulmonary edema. Radiology 1978;126:19-24.

3 Pool PE, Vogel JHK, Blount SG Jr. Congenital unilateral absence of pulmonary artery: importance of flow in pulmonary hypertension. Am J Cardiol 1962;10:706-32.

4 Trapnell DH, Thurston JGB. Unilateral pulmonary edema after pleural aspiration. Lancet 1970;i:1367-9.

5 Bahl OP, Oliver GC, Rockoff SD, Parker BM. Localized pulmonary edema: an unusual presentation of left heart failure. Chest 1971;60:277-80.

6 Saleh M, Miles AI, Lasser RP. Unilateral pulmonary edema in Swyer-James syndrome. Chest 1974;66:594-7.

7 Kieffer SA, Amplatz K, Anderson RC, et al. Proximal interruption of a pulmonary artery. Roentgen features and interruption of a pulmonary artery. Roen
surgical correction. $A J R$ 1965;95:592-7. 